Est Ag 41 (2006) 45-60

\title{
La Eucaristía, Sacramentum pietatis
}

En un artículo recientemente publicado en la Revista Agustiniana $^{1}$, el docto agustinólogo francés G. Folliet se ocupa de la célebre definición agustiniana de la Eucaristía: « Oh sacramento de piedad! ¡Oh signo de unidad! ¡Oh vínculo de caridad!» (O sacramentum pietatis, o signum unitatis, o uinculum caritatis $)^{2}$. El estudio consta de dos partes, la primera dedicada a la interpretación del primer miembro de la definición y la segunda a ponderar la amplia difusión de la terna. La que ha llamado nuestra atención y está en el origen de estas páginas ha sido precisamente la primera.

El esfuerzo del autor va dirigido a descubrir el significado del primer miembro de la frase: «iOh sacramento de piedad!». Un repaso por diversas traducciones a las lenguas vernáculas del sustantivo pietas le permite constatar la diversidad de interpretaciones y, también, su imprecisión ${ }^{3}$. Expuesto el parecer de otros traductores, presenta su opinión en estos términos: «Nosotros pensamos, pues, que, en las palabras de Agustín "o sacramentum pietatis", la comprensión de pietas en el sentido de culto a Dios es incontestable. De manera que las otras acepciones de la palabra pietas como las de piedad divina respecto del hombre, o de amor, de bondad o de misericordia de Dios de cara al hombre... nos parece que traicionan el pensamiento de Agustín e introducen un contrasentido en la expresión " $O$ sacramentum pietatis, o signum unitatis, o uinculum caritatis"4. $\mathrm{El}$ argumento básico del autor es que el santo, de forma continua a lo largo de toda su vida de escritor eclesiástico, reserva a este término pietas la acepción propia de acto de

1 G. Fólliet, Une définition augustinienne de l'Eucharistie, en Revista Agustiniana 45 (2004) 519-552.

2 Io. eu. tr. 26,13.

3 «La plupart des interprètes s'en tiennent à la traduction littérale de pietas: Pietät, piety, piété, sans préciser pour autant s'il s'agit de la piété de l'homme à l'egard de Dieu, ou de la piété de Dieu envers l'homme. D'autres traducteurs proposent des versions aussi imprécises amor, amour, amore, Gottseligkeit, the true faith pouvant s'entendre de l'amour de Dieu por l'homme ou de l'amour de l'homme pour Dieu. Figurent aussi dans certaines traductions du mot pietas des interprétations plus explicites, mais non moins contestables, telles que beauté, bonté ou misericorde qui insistent sur des attributs de Dieu au bénéfice de l'homme» (Ib., p. 521-522).

4 Ib. p. $525-526$. 
religión, de culto a Dios de parte del hombre, esto es, la actitud de acción de gracias, de una manifestación de amor de la criatura hacia su creador ${ }^{5}$. Para avalar esa comprensión del término aduce más de veinte textos agustinianos. Otro argumento alegado es que la expresión sólo tiene sentido en su totalidad si se sobreentiende la palabra ecclesiae como añadido a cada uno de los tres miembros. Como esta palabra se adivina espontáneamente al final del segundo y del tercer miembro signum unitatis (ecclesiae), uinculum caritatis (ecclesiae), él juzga que se impone lógicamente para la mejor inteligencia del primer miembro: sacramentum pietatis (ecclesiae), entendiéndose esta palabra ecclesia como sinónimo del Cuerpo de Cristo ${ }^{6}$. En otros textos agustinianos, especialmente de La ciudad de Dios, encuentra la vinculación explícita entre el acto de culto a Dios y la Eucaristía 7, algo que le parece estar en la línea del comentario agustiniano a Juan 6,49-51 en sus Tratados sobre el evangelio de san Juan ${ }^{8} 26$ en que se halla el célebre texto 9. «¿Cómo se puede dudar -escribe- del significado de la palabra pietas que no puede expresar sino la comunión del cristiano en la ofrenda del cuerpo de Cristo mediante su muerte, ofrenda conjunta de Cristo y de la Iglesia, y presentada a Dios en un mismo acto de culto, en un mismo homenaje?»10. Para apoyar o justificar su interpretación, el autor apela también a 1 Tim 3,16-17 en que figura la expresión sacramentum pietatis, a propósito del misterio de la Encarnación y de la Iglesia, texto citado por el santo una decena de veces ${ }^{11}$.

G. Folliet termina esta parte de su estudio con estas palabras: «En conclusión, nosotros creemos poder decir que toda la riqueza del sacramento de la eucaristía, es decir, su rol sacrificial, su realidad eclesial y su finalidad caritativa, se halla adecuadamente expresada en la fórmula agustiniana " $O$ sacramentum pietatis, o signum unitatis, o uinculum caritatis", bien entendido que estos elementos sólo tienen valor en su complementariedad» 12 .

Como hemos visto, G. Folliet valora su interpretación como «incontestable». A nuestro parecer, se trata de una interpretación posible, ignoramos si también probable pero, en todo caso, no la única. Presentar otra interpretación posible, precisamente una descartada por él, es el objetivo de

\footnotetext{
$5 \mathrm{Ib}$. p. 522.

6 Ib. p. 526.

${ }^{7}$ Ib. p. 526 .

${ }^{8}$ En adelante nos referiremos a él sólo con Tratado.

${ }^{9} \mathrm{Ib}$. p. 528.

$10 \mathrm{Ib}$. p. 529.

$11 \mathrm{Ib}$. p. 530.

$12 \mathrm{Ib}$. p. 532.
} 
estas páginas. Consiste en entender la «piedad» como «piedad» de Dios para con los hombres, no de los hombres para con Dios, además de enmarcar la definición agustiniana en un contexto implícitamente trinitario.

1. Pietas es una palabra de uso frecuentísimo en san Agustín ${ }^{13}$. Lo normal es que indique una virtud humana, las más de las veces un modo de comportarse del hombre frente a Dios. Pero el santo reconoce también la pietas en Dios. En La ciudad de Dios afirma que el pueblo acostumbra a utilizar la palabra pietas con referencia a las obras de misericordia, razón por la que también a Dios se le llame pius ${ }^{14}$. Ya en concreto, él considera a Dios pius por haber entregado a su Hijo por los hombres ${ }^{15}$, hecho que incluye tanto la muerte como la encarnación que la hace posible ${ }^{16}$. Más aún, en las Confesiones le invoca como Pater pietatis ${ }^{17}$. Esta constatación debe, pues, llevar a la cautela. Indiscutiblemente los textos en que san Agustín define la pietas como culto a Dios son numerosos y abarcan un amplio arco de la vida del pastor de Hipona. Pero eso no conlleva necesariamente tener que interpretar el concepto en ese sentido también en el texto que nos ocupa. El que en unos contextos el santo dé esa definición de pietas no excluye que en otros la entienda de otra manera. Ni se ha de olvidar que la definición de pietas como culto a Dios no aparece en relación con el sacramentum pietatis. No nos parece, pues, incuestionable la interpretación de G. Folliet. Tratemos de ver cómo es posible la otra interpretación antes apuntada.

2. Una fórmula tan precisa y concisa ${ }^{18}$ tiene todas las trazas de ser una síntesis ordenada de todo el desarrollo anterior. Procede, pues, examinar el contexto previo. Un dato objetivo es que en el Tratado 26 el santo comenta el pasaje de Jn 6,41-59. Este texto juánico se puede dividir en dos partes, cada una de las cuales contiene una objeción de los judíos y la réplica de Jesús. La primera abarca los versículos 41-51, de los que dos (vv. 41-42) relatan lo dicho por ellos, y los restantes (vv. 43-51) la respuesta de Jesús. En el

\footnotetext{
13 El sustantivo pietas, en sus diversos casos, aparece 879 veces y el adjetivo pius, también en sus diversos casos, 1.160. Datos tomados del CAG2.

14 Ciu. 10,1 (3); S. 55,4,4.

15 Ep. 93,2,7: «Cum ergo et pater tradiderit filium suum et ipse Christus corpus suum et Iudas dominum suum, cur in hac traditione deus est pius et homo reus, nisi in re una, quam fecerunt, causa non una est, qua fecerunt?».

16 Sobre Dios como pius, cf. también c. Iul. imp. 1,67.81; 3,83.

17 Conf: $13,24,36$

$18 \mathrm{El}$ autor escribe: «Il fallait tout le génie d'Augustin pour formuler une définition aussi prégnante du sacrement» (Ib. p. 520).
} 
comentario agustiniano ocupa los parágrafos del 1 al 13. La segunda parte se extiende del versillo 52 al 5919 , de los que uno (v. 52) refiere la dificultad expresada por los judíos y los restantes (vv. 53-59), la respuesta de Jesús. En el comentario agustiniano se ocupan de ella los parágrafos 14-20.

Como la definición de la Eucaristía que nos ocupa se halla en el parágrafo 13, nuestro interés se limita a la primera de las dos partes antes señaladas, en la que está incluida, y no a toda ella, sino sólo a la respuesta de Jesús. El núcleo de la misma es este versículo: «Nadie puede venir a mí, si el Padre que me ha enviado no lo atrae» (v. 44a). Él menciona a los dos protagonistas, por así decir, de todo el pasaje: Jesucristo y el Padre. De hecho, ambas personas determinan la estructura de lo que sigue. La del Padre está en el centro de los primeros versículos (vv. 44-47); la del Hijo (Jesucristo) en el de los siguientes (vv. 47-51). Este particular ya nos sitúa en contexto trinitario, aunque incompleto, porque no aparece mencionado el Espíritu Santo.

En su comentario, el predicador de Hipona comienza como meticuloso exegeta, pero acaba como fino teólogo. Después de haber hablado, ateniéndose al texto, sólo del Padre y de Jesucristo, para completar la Trinidad introduce en escena al Espíritu Santo, ausente del pasaje juánico. De esta manera hace explícito lo que él advertía implícito en él. La ocasión se la brinda la dificultad que le ofrecía la explicación del versículo 51: «el pan que yo daré es mi carne por la vida del mundo». La interpretación eucarística del texto le lleva al Cuerpo de Cristo, que, animado por el Espíritu Santo, recibe de él la vida. Y justamente a continuación de esta breve mención del Espíritu Santo, como habiendo completado ya el cuadro, es cuando prorrumpe en la conocida exclamación: « $\mathrm{O}$ h sacramento de piedad! ¡Oh signo de unidad! ¡Oh vínculo de caridad!». A partir de aquí no nos parece descaminado ver en los distintos miembros de la frase una referencia a cada una de las Personas divinas, por su orden. Esto es, en el «sacramento de piedad» una referencia al Padre; en el «signo de unidad» una referencia al Hijo, y en el «vínculo de caridad» una referencia al Espíritu Santo.

3. Si se acepta que el «sacramento de piedad» guarda relación con el Padre hay que aceptar que la guarda también de forma específica la «piedad». Pero lo que hay que discernir es si se trata de la «piedad» del hombre para con Dios, como piensa G. Folliet, o, al contrario, de la «piedad» de

$19 \mathrm{Al}$ versículo 53 hace referencia de paso ya en el parágrafo 13 , pero su explicación es objeto del parágrafo 14 . 
Dios para con los hombres. A nuestro parecer, el texto tiene más sentido en el conjunto si se entiende esa «piedad» como el amor de Dios, precisamente en cuanto Padre, hacia los hombres. Lo deducimos del comentario agustiniano que expone pródigamente en qué se manifiesta ese amor.

Si retrocedemos un poco en el texto juánico encontramos la manifestación de ese amor en el don del pan «bajado del cielo». En efecto -dice Jesús a los judíos- fue el Padre, no Moisés, quien les dio el verdadero pan del cielo. San Agustín matiza que lo que el Padre les dio no fue el maná, sino el pan que el maná significaba, el Señor Jesús en Persona, el pan que da la vida al mundo (cf. Jn 6,32-33) ${ }^{20}$. Es evidente que con la expresión «bajado del cielo» se hace referencia a la encarnación.

Pero volvamos al pasaje juánico que nos ocupa. De su lectura se deriva que ese amor de Dios Padre se manifiesta -resumiendo- en que él nos arrastra hacia Cristo (v. 44), el pan de vida (v. 48), el pan vivo que ha bajado del cielo, un pan tal que quien lo come no muere (v. 50) sino que vivirá para siempre (v. 51). En su comentario, el obispo de Hipona sigue, respecto del hombre, dos líneas: una objetiva y otra subjetiva. La objetiva consiste en exponer cómo lo arrastra el Padre. Según el santo, el Padre arrastra hacia Jesucristo a quienes creen en él como Hijo precisamente porque piensan que tiene a Dios por Padre (cf. Mt 16,17)21. Los arrastra al revelarles su condición de Hijo suyo y, por tanto, su condición divina, lo que le identifica con valores como la Verdad, la Felicidad, la Justicia, que se resumen en el de Vida eterna. El texto del profeta Isaías citado por Jesús: Todos serán enseñados por Dios (Jn 6,45; cf. Is 54,13), sirve al predicador para explicar ulteriormente lo que significa ese ser arrastrados por el Padre. El Padre -comenta- enseña por su Palabra, la que existía en el principio junto a él (Jn 1,1), Palabra que se hizo carne (Jn 1,14) para que los hombres que viven en la carne pudieran escucharla ${ }^{22}$. Si Cristo no hubiera asumido la carne, el hombre no habría podido escuchar al Padre. «¿Qué significa ser arrastrados por el Padre sino aprender del Padre? ¿Qué significa aprender del Padre sino escuchar al Padre? ¿Qué significa escuchar al Padre, sino escuchar la Palabra del Padre, esto es, a mí (Jesucristo)?»23. Escuchar a Cristo es creer

20 Io. eu. tr. 25,13: «Deus dat panem. Sed quem panem? forte manna? non, sed panem quem significauit manna, ipsum scilicet dominum Iesum».

21 Ib. 26,5: «Trahit pater ad filium eos qui propterea credunt in filium, quia eum cogitant patrem habere deum».

22 Cf. $I b .26,8$.

23 Ib. 26,9: «Quid est autem uos trahi a patre, nisi discere a patre? quid est discere a patre, nisi audire a patre? quid est audire a patre, nisi audire uerbum patris, id est me?». 
en Cristo y quien cree en Cristo tiene la vida eterna (cf. Jn 6,47). «Quiso revelar qué es él, porque pudo decir en síntesis: 'Quien cree en mí me tiene a mí, pues Cristo es verdadero Dios y la Vida eterna. Quien, pues, cree en mí -afirma- viene a mí; y el que viene a mí me tiene a mí. Ahora bien, ¿qué es tenerme a mí? Tener vida eterna» ${ }^{24}$. «La vida asumió la muerte, la Vida eterna quiso morir, pero con lo tuyo, no con lo suyo; de ti tomó con qué morir por ti ${ }^{25}$. En el comienzo está la encarnación de la Palabra ${ }^{26}$, que incluye también su muerte, y al final está la vida eterna del hombre. Al hombre le arrastra la vida, por eso le arrastra Cristo y porque a Cristo le revela el Padre es legítimo decir que es el Padre quien arrastra al hombre hacia Cristo. Este revelar a Cristo al hombre es poner ante los ojos del hombre aquello que él más desea.

En efecto, como indicamos, el obispo de Hipona no se queda en la perspectiva objetiva señalada. También entra en la perspectiva subjetiva del hombre destinatario de la relevación y objeto del arrastre. De hecho, no se siente arrastrado hacia Cristo cualquier hombre sino sólo aquel que se deleita en la Verdad, la Felicidad, la Justicia y la Vida eterna ${ }^{27}$. Ahora bien, todo eso es Jesucristo en cuanto Hijo de Dios y Dios. El texto es bien conocido: «Preséntame uno que ame y entenderá lo que digo. Presenta un deseoso, presenta un hambriento; presenta uno, desterrado y sediento en esta soledad, y que suspira por la patria eterna; presenta uno así y sabrá qué digo» ${ }^{28}$. Si los hombres se sienten arrastrados hacia Jesucristo es porque el contenido de la revelación del Padre respecto de él coincide con las aspiraciones de ellos. «En efecto, ¿qué desea el alma más vivamente que la verdad? ¿De qué debe tener ávida la garganta, por qué debe desear que dentro esté sano el paladar con que juzgar la Verdad, sino para comer y beber

24 Ib. 26,10: «Reuelare se uoluit quid esset, nam compendio dicere potuit: qui credit in me, habet me. Ipse enim Christus uerus deus est et uita aeterna. Qui ergo credit in me, inquit, it in me; et qui it in me, habet me. Quid est autem habere me? habere uitam aeternam».

25 Ib. 26,10: «Vita aeterna mortem assumsit, uita aeterna mori uoluit; sed de tuo, non de suo; accepit a te, ubi moreretur pro te».

${ }^{26}$ La referencia a la encarnación aparece de nuevo poco al comienzo del parágrafo 13, a través de la cita juánica: «Yo soy el pan vivo porque he bajado del cielo (Jn 6,51). Vivo precisamente porque he bajado del cielo».

27 Ib. 26,4: «quanto fortius nos dicere debemus trahi hominem ad Christum, qui delectatur ueritate, delectatur beatitudine, delectatur iustitia, delectatur sempiterna uita, quod totum Christus est?».

28 Ib.: «Da amantem, et sentit quod dico. da desiderantem, da esurientem, da in ista solitudine peregrinantem atque sitientem, et fontem aeternae patriae suspirantem, da talem, et scit quid dicam. Si autem frigido loquor, nescit quid loquor». 
la Sabiduría, la Justicia, la Verdad, la Eternidad?»29. En la compañía de Cristo, el hombre hambriento y sediento de los valores mencionados se encuentra bien pagado. «Le pago con lo que ama, le pago con lo que espera, verá lo que creyó sin verlo, comerá lo que hambrea, se saciará de eso de que tiene sed» 30 .

Y ahora la pregunta: ¿No es prueba del amor de Dios Padre a los hombres el arrastrar a los hombres a Jesucristo, en quien pueden ver satisfecho su deseo de vida eterna, síntesis de todos los demás? ¿No es prueba de ese mismo amor el haber revelado que Jesucristo es su Hijo, quien, por su condición divina, puede colmar los deseos de eternidad del hombre? ¿No es prueba de ese amor el haberle dado a su Hijo, portador de vida eterna y Vida eterna él mismo? ¿No es prueba de ese amor el darle la posibilidad de comer del Pan de vida bajado del cielo, participando así de ella? Por último, ¿no es prueba de ese amor la encarnación, condición para todo lo anterior? Todo esto puede entenderse muy bien como explicitación de la «piedad» del Padre hacia los hombres. La Eucaristía, en cuanto don de ese Pan de Vida, es la expresión concreta de esa «piedad», de ese amor de Dios Padre por el hombre.

Pero la Eucaristía es prueba, no manifestación de ese amor paterno; es «sacramentum de piedad». Es realidad presente -por eso es prueba-, pero oculta, no visible -por eso no se puede hablar de manifestación, sino sólo de sacramentum-. A propósito de esa vida eterna, san Agustín distingue bien: no lo que aparece a la vista, sino lo que está oculto ${ }^{31}$.

4. A G. Folliet no se le oculta que el «sacramento de piedad» de la cita agustiniana remite probablemente a $1 \mathrm{Tim} 3,16$, texto que aparece repetidas veces en las páginas del santo. En el dato ve un argumento más a favor de su interpretación. «En las diversas traducciones de la palabra pietas... son las palabras piedad y amor, y sus correspondientes literales en las distintas lenguas, las que aparecen repetidamente, pero siempre para explicitar el misterio de la encarnación de Cristo en cuanto una "démarche", una manifestación de veneración, de adoración, de culto referido a Dios» 32 . Pero el

29 Ib. 26,5: «Quid enim fortius desiderat anima quam ueritatem? Quo auidas fauces habere debet, unde optare ut sanum sit intus palatum uera iudicandi, nisi ut manducet et bibat sapientiam, iustitiam, ueritatem, aeternitatem?».

30 Ib. 26,6: «Reddo illi quod amat, reddo quod sperat; uidebit quod adhuc non uidendo credidit; manducabit quod esurit, saturabitur eo quod sitit. Ubi? In resurrectione mortuorum, quia ego resuscitabo eum in nouissimo die [Io 6,44]».

$31 \mathrm{Ib} .26,10:$ «... non quod patet, sed quod latet».

32 «Une définition...», p. 530 . La cursiva es del autor. 
autor se ha limitado a hacer una afirmación, sin entrar en los textos. Es conveniente, pues, acercarse a ellos para examinar hasta qué punto responde a verdad lo afirmado. Se trata de saber si en ellos la encarnación aparece en contexto de dirección ascendente, de veneración y culto del hombre a Dios, o descendente, de amor de Dios al hombre. El autor mismo nos aporta las referencias agustinianas.

Varias de ellas no resuelven nada al respecto ${ }^{33}$. Pero otras nos parecen esclarecedoras. En un pasaje de la obra La trinidad san Agustín expone en qué sentido ha de entenderse el envío del Hijo por el Padre y cómo este envío no implica desigualdad entre las dos divinas personas, salvo el hecho de que una es el Padre y otra el Hijo. Cuando pasa a hablar ya en concreto de la encarnación, acontecida en la plenitud de los tiempos, señala que el Hijo de Dios -la Sabiduría divina- no fue enviado a llenar a los ángeles ni a hacerse ángel; tampoco a morar con los hombres o en los hombres, como sucedió, antes de la encarnación, en tiempo de los profetas, sino para que se encarnase, es decir, se hiciese hombre; un sacramento que se revelaría en el futuro, en el que estaría la salvación de los sabios y santos nacidos de mujer antes de su encarnación, y en el cual, una vez hecho realidad y anunciado, está la salvación de todos los que creen, esperan y aman. Y a continuación añade la cita de 1 Tim 3,1634. El «sacramento de piedad» aquí mencionado no guarda relación alguna cor: ningún debido tributo que el hombre pague a Dios, sino sólo con su valor salvífico para los hombres anteriores y posteriores a Cristo.

En El Génesis a la letra el «sacramento de piedad»viene a identificarse con el contenido de Ef 3,8-11, texto en que san Pablo afirma que se le ha dado la gracia de anunciar a los gentiles las insondables riquezas de Cristo, y esclarecer cómo se ha dispensado el misterio escondido desde los siglos en Dios ${ }^{35}$. Tampoco en este pasaje la mención del «sacramento de piedad» comporta ninguna relación del hombre con Dios, pero sí una referencia a la salvación que, a través de Jesucristo, Dios aporta a los hombres ${ }^{36}$.

La carta 157 asocia el «sacramento de piedad» que se manifestó en la carne a la encarnación, esto es, a la venida de Cristo que resplandeció para todos los pueblos que iban a ser llamados ${ }^{37}$. Una vez más, san Agustín omite en el contexto del «sacramento de piedad» la referencia a cualquier acto de culto a Dios del hombre, señalando sólo la llamada de los pueblos, acción de Dios en beneficio del hombre.

\footnotetext{
33 Así Cath. fr. 24,70; Ep. 199,12,50; S. 204,1.

34 Trin. 4,20,27.

35 Gen Lit. 5,19,39.

$36 \mathrm{Ib} .5,19,38$.

37 Ep. $157,4,24$.
} 
El Tratado 72 compara la creación con el «sacramento de piedad» en estos términos: «Vea y juzgue quien pueda si es mayor obra crear justos que hacer justos a los pecadores; porque, si ambas obras requieren igual poder, esta requiere mayor misericordia» ${ }^{38}$. De nuevo, lo que pone de relieve el santo es lo que obra Dios a favor de los hombres, no culto alguno que el hombre tribute a Dios. Y es significativo aquí que el "sacramento de pie$d a d »$ esté asociado a una «mayor misericordia».

Por último, en la obrita La fe en lo que no se ve, el gran «sacramento de piedad» va asociado al gran poder del crucificado para conquistar los pueblos, sólo explicable porque Dios asumió al hombre ${ }^{39}$. Tampoco aquí hay rastro de algo que el hombre ofrezca a Dios en este contexto.

La conclusión que cabe extraer de este recorrido por los textos es esta: en la medida en que el «sacramento de piedad» de la definición agustiniana de la Eucaristía incluye la referencia a la encarnación y a su prolongación, la Iglesia, la «piedad» no cabe entenderla como tributo de veneración y culto que el hombre tribute a Dios, sino como expresión del amor de Dios por el hombre que está en el origen de la encarnación misma. Esa «piedad» más que al culto del hombre, remite a la misericordia divina. Estamos en la misma dirección señalada para el Tratado 26.

A la misma conclusión nos lleva el sermón 229 (= Denis 6), todo él una catequesis eucarística dirigida en la mañana del domingo de Pascua a los neófitos bautizados pocas horas antes en la Vigila Pascual. El predicador abre prácticamente su catequesis con una referencia a la Encarnación. Después de indicar que el pan y el vino que estaban viendo sobre el altar se convierten en el cuerpo y la sangre de la Palabra cuando se les aplica la palabra, continúa: «En efecto, el Señor, la Palabra que existía en el principio, la Palabra que estaba junto a Dios, y la Palabra que era Dios (Jn 1,1), debido a su misericordia, que le impidió despreciar lo que había creado a su imagen (cf. Gén 1,26-27), se hizo carne y habitó entre nosotros (Jn 1,14), como sabéis. Pues la Palabra misma asumió al hombre, es decir, al alma y a la carne del hombre, y se hizo hombre permaneciendo Dios. Por ello, y dado que además sufrió por nosotros, nos confió en este sacramento su cuerpo y sangre, en que nos transformó también a nosotros mismos. En efecto, también nosotros nos hemos convertido en su cuerpo y, por su misericordia, somos lo que recibimos» ${ }^{40}$. De este texto cabe señalar, ante todo, la vinculación entre la encarnación y la Eucaristía; luego el explicar la encarnación

38 Io. eu. tr. $72,3$.

${ }^{39}$ F. inuis. 7,10 .

40 S. 229,1. La autenticidad de este sermón no es aceptada por todos los estudiosos. 
y la Eucaristía desde la misericordia divina; por último, se puede percibir un cierto paralelismo con el Tratado 26,13: la referencia a la encarnación y la realidad del constituirse de los cristianos en el cuerpo de Cristo.

5. Que san Agustín entiende la Eucaristía como un acto de culto a Dios es algo que no admite discusión. Los textos citados por el autor, sobre todo los tomados de La ciudad de Dios ${ }^{41}$, no dejan lugar a la menor duda. También es evidente que en ese contexto el santo recurre al término sacramentum. Pero la evidencia desaparece respecto a si el término sacramentum utilizado en este contexto hace referencia a la misma realidad que el «sacramento de piedad» que nos ocupa. Nosotros lo dudamos. Aceptando, como ya indicamos antes, que la definición trimembre de la Eucaristía es síntesis del desarrollo previo, nos parecen demasiado tenues las referencias explícitas en el Tratado 26 a la Eucaristía como sacrificio indicadas por G. Folliet, una de las cuales aparece en un contexto moral ${ }^{42}$.

6. G. Folliet interpreta el «vínculo de caridad» en clave moral. Con referencia a ese tercer miembro de la frase agustiniana, leemos en su artículo: «... la caritas, la Eucaristía lazo de amor en el participar de un mismo pan»43, y en otro: «... toda la riqueza de la Eucaristía, o sea, su rol sacrificial, su realidad eclesial y su finalidad caritativa ${ }^{44}$ ». Ahora bien, nosotros no vemos que en el texto se hable para nada de las exigencias caritativas de la Eucaristía. Por ello, a nuestro parecer, más que en clave moral, hay que entenderlo en clave teológica, esto es, con referencia a la Persona del Espíritu Santo. Es lo que cabe concluir si -volvemos a decirlo- hay que ver la definición eucarística trimembre como una síntesis del desarrollo anterior y si incluye una implícita referencia trinitaria. De hecho, en las líneas inmediatamente anteriores el predicador ha hablado del Espíritu de Cristo que vivifica al Cuerpo de Cristo $^{45}$, referencia clara a la idea agustiniana del Espíritu Santo como

41 Сіи 10,6 y $10,20.19$.

42 Io. eu. tr. 26,11: «... innocentiam ad altare apportate»; 26,12: «Hunc panem significauit manna, hunc panem significauit altare Dei...Percussa est petra de uirga bis; gemina percussio, duo ligna crucis significat». La cursiva es del autor.

43 «Une définition..., p. 520.

$44 \mathrm{Ib}$., p. 532. La cursiva es nuestra.

45 Io. eu. tr. 26,13: «Fiant corpus Christi, si uolunt uiuere de spiritu Christi. De spiritu Christi non uiuit, nisi corpus Christi. Intellegite, fratres mei, quid dixerim... corpus utique meum uiuit de spiritu meo. Vis ergo et tu uiuere de spiritu Christi? In corpore esto Christi. Numquid enim corpus meum uiuit de spiritu tuo? Meum uiuit de spiritu meo, et tuum de tuo. Non potest uiuere corpus Christi, nisi de spiritu Christi. Inde est quod exponens nobis apostolus Paulus hunc panem, unus panis, inquit, unum corpus multi sumus [1 Cor 10,17]». 
alma de la Iglesia ${ }^{46}$. El Cuerpo de Cristo no puede vivir si no mantiene la unidad entre cabeza y miembros y de los miembros entre sí. En eso consiste la tarea vivificadora del Espíritu. A esa unidad alude la cita de 1 Cor 10,17 , texto fundamental en la doctrina eucarística del santo; unidad que es, sin duda, producto de la caridad, don del Espíritu (cf. Rom 5,547). El «vínculo de caridad», pues, no hace referencia inmediata a ninguna acción caritativa, sino a la obra que el Espíritu Santo realiza en el Cuerpo de Cristo.

7. Los tres miembros de la frase constan de un sustantivo en nominativo (sacramentum, signum, uinculum) seguidos de un genitivo de pertenencia o de cualidad (pietatis, unitatis, caritatis respectivamente). G. Folliet supone que estos sustantivos que van en genitivo llevan implícito un complemento del nombre que es para los tres el mismo: ecclesiae: sacramentum pietatis (ecclesiae), signum unitatis (ecclesiae), uinculum unitatis (ecclesiae). Nosotros, que también suponemos implícito un complemento del nombre, en línea con lo que venimos exponiendo preferimos asignar a cada uno de ellos su complemento del nombre propio: sacramentum pietatis (Patris), signum unitatis (Christi=Filii), uinculum caritatis (Spiritus Sancti). En los tres casos se trata de genitivos posesivos o de pertenencia. La piedad es del Padre, la unidad es del Hijo y la caridad es del Espíritu Santo.

8. Entonces, ¿descartamos del todo a la Iglesia en la interpretación del texto agustiniano? En absoluto. Es más, hay que suponerla presente en cada uno de los miembros de la frase. Pero no con función de complemento de nombre, sino con otras funciones, distintas en cada caso. Esta es nuestra propuesta: la Eucaristía es sacramentum pietatis (Patris erga ecclesiam), signum unitatis (Christi ecclesiae) y uinculum caritatis (Spiritus sancti in ecclesia). La Eucaristía encierra (sacramentum) en sí el amor del Padre hacia la Iglesia; la Eucaristía expresa (signum) la unión de Cristo con la Iglesia o la unidad entre Cristo y la Iglesia; la Eucaristía es lazo de unidad (uinculum) en la Iglesia gracias a la caridad, don del Espíritu santo. Lo dicho lo podemos explicitar un poco más: la Eucaristía encierra todo el amor del Padre a los hombres, manifestado en haberles entregado a su Hijo para que, por él,

46 Cf. $S .267,4,4 ; 268,2$.

47 Prescindiendo de que es uno de los pasajes bíblicos más frecuentemente citados por san Agustín, el santo lo ha citado al comienzo del Tratado. "Unde ista caritas homini? Ipsum audiamus: caritas, inquit, dei difusa est in cordibus nostris, per Spiritum Sanctum qui datus est nobis (Rom 5,5). Daturus ergo Dominus Spiritum Sanctum, dixit se panem qui de coelo descendit, hortans ut credamus in eum" (In. eu. tr. 26,1). 
el Pan de vida bajado del cielo (encarnación), puedan conseguir la vida eterna; la Eucaristía expresa la unión como miembros del único Cuerpo de Cristo de todos los fieles que comulgan a su cuerpo y sangre; la Eucaristía es lazo de unidad en la Iglesia porque los fieles, al participar del Cuerpo de Cristo y, en consecuencia, del Espíritu que lo anima, reciben el don que los mantiene unidos, la caridad.

9. Como apéndice puede ser provechoso examinar también la parte del texto que sigue a la célebre terna hasta la conclusión del parágrafo. Quizá nos aporte luces complementarias para entenderla, dado que, significativamente, contiene otras tres ternas que cabe presuponer están en correspondencia con la anterior. La primera de ellas es la siguiente: «Quien quiere vivir tiene donde vivir, tiene de qué vivir» ${ }^{48}$. Ahora se trata de averiguar si existe una correspondencia entre los miembros de esta terna y los de la primera. Respecto del segundo y del tercer miembro resulta fácil advertirla: el «tiene donde vivir» parece remitir a la Eucaristía como signum unitatis: el fiel hallará su vida allí donde tiene lugar su unión con Cristo, esto es, en su Cuerpo eclesial; el "tiene de qué vivir" parece remitir a la Eucaristía como uinculum caritatis: el fiel encontrará en ella la caridad, indicadora de la presencia del Espíritu Santo, de quien procede tanto la caridad (Rom 5,5) como la vida, según ha dicho el predicador poco antes ${ }^{49}$. Si se puede constatar la correspondencia respecto del segundo y tercer miembros, ¿no se dará también respecto del primero: «quien quiere vivir»? No cabe duda de que estas palabras guardan relación con los versículos que el santo está comentando (Jn 6, 51-52). Pero si los versículos afirman que comer del pan que da Cristo otorga la vida eterna (Si alguien come de este pan, vivirá eternamente; y el pan que yo le daré es mi carne por la vida del mundo50), nada indican de que el posible receptor desee esa vida. Esta realidad, sin embargo, está bien presente en los parágrafos que preceden. Citamos tres textos: "Además, si a un poeta fue lícito decir: "Su placer tira de cada cual"51 -no la necesidad, sino el placer; no la obligación, sino la delectación-, ¿con cuánta más fuerza debemos nosotros decir que hacia Cristo se tira del hombre que se deleita en la verdad, se deleita en la dicha, se deleita en la justi-

\footnotetext{
48 Io. eu. tr. 6,13: "qui uult uiuere, habet ubi uiuat, habet unde uiuat".

${ }^{49}$ En el mismo parágrafo decimotercero, el predicador ha introducido al Espíritu Santo en cuanto alma del Cuerpo de Cristo para explicar que quien coma el cuerpo de Cristo tendrá la vida.

50 Cf. también Io. eu. tr. 26,10 donde se detiene en Cristo como vida, en relación con Jn 6,47: En verdad, en verdad os digo: quien cree en mí tiene vida eterna.

51 VIRGILIUS, Eglog. 2.
} 
cia, se deleita en la vida sempiterna, todo lo cual es Cristo?»52. «En efecto, de qué debe tener ávida la garganta, por qué debe desear que dentro esté sano el paladar con que juzgar la verdad, sino para comer y beber la sabiduría, la justicia, la verdad, la eternidad?»53. «Por eso, cuando dijo: Nadie viene a mí si el Padre que me envió no tira de él, ¿qué añadió? Y yo lo resucitaré en el último día (Jn 6,44). Le pago con lo que ama, le pago con lo que espera; verá lo que creyó sin verlo, comerá lo que hambrea, se saciará de eso de lo que tiene sed. ¿Cuándo? En la resurrección de los muertos, porque yo lo resucitaré en el último día» ${ }^{54}$. No es fácil, es cierto, ver una correspondencia entre «sacramento de piedad»y «quien quiere vivir». Pero una coincidencia sí se puede constatar: tanto un sintagma como el otro encuentran explicación en los primeros parágrafos del Tratado. Yendo un poco más lejos, se podría sostener que uno y otro se refieren a lo mismo, pero desde perspectivas diferentes: El «quien desea vivir» se pone en la perspectiva del hombre, indicando lo que desea, mientras que «sacramento de piedad»se pone en la perspectiva de Dios, mostrando su amor manifestado en haberle dado la posibilidad de satisfacer su deseo.

10. El texto agustiniano continúa en estos términos: «Acérquese, crea, incorpórese para ser vivificado ${ }^{55}$. Tenemos aquí la segunda terna; en efecto, la frase tiene una estructura trimembre en su forma literaria y en su contenido doctrinal, pero sin que coincidan ambos aspectos. A nivel literario, salta a la vista la terna constituida por los tres imperativos: acérquese, crea, incorpórese. A nivel de contenido en cambio, parece más adecuado establecer otra división: acercarse (= creer), incorporarse, ser vivificado. Centrando nuestra atención en esta última, formulamos la misma pregunta de antes, esto es, si existe correspondencia entre los miembros de esta terna y los de la primera. De nuevo nos resulta fácil advertirla para el segundo y el tercero. De hecho, el «incorpórese» se compadece bien con el signum uni-

52 Io. eu. tr. 26,4: «porro si poetae dicere licuit: trahit sua quemque uoluptas, non necessitas, sed uoluptas; non obligatio, sed delectatio, quanto fortius nos dicere debemus trahi hominem ad Christum, qui delectatur ueritate, delectatur beatitudine, delectatur iustitia, delectatur sempiterna uita, quod totum Christus est?».

$53 \mathrm{Ib} .26,5$.

54 Ib. 26,6: «Ideo cum dixisset: nemo uenit ad me, nisi pater qui misit me, traxerit eum [Io $6,44]$, quid subiecit? et ego resuscitabo eum in nouissimo die [Io 6,44]. Reddo illi quod amat, reddo quod sperat; uidebit quod adhuc non uidendo credidit; manducabit quod esurit, saturabitur eo quod sitit. ubi? in resurrectione mortuorum, quia ego resuscitabo eum in nouissimo die [Io 6,44]».

55 Ib. 26,13: «accedat, credat, incorporetur, ut uiuificetur». 
tatis: el predicador invita al oyente a incorporarse al Cuerpo eclesial, unido a Cristo, su Cabeza, unión expresada en la Eucaristía; a su vez, el «para ser vivificado» se compadece bien con el uinculum caritatis: la incorporación al Cuerpo de Cristo acontece mediante la caridad, que, en cuanto don del Espíritu Santo (cf. Rom 5,5), testimonia su presencia vivificadora, como el predicador ha dicho poco antes. Nos queda el primer miembro de la terna, contemplada en su contenido doctrinal; en él integramos los dos primeros imperativos: «acércate» y «cree». ¿Por qué los dos? Porque para san Agustín el acercarse el hombre a Cristo, resultado de que el Padre tire de él, se identifica con la fe en Cristo ${ }^{56}$, tema tratado en los primeros parágrafos del Tratado. No parece descaminado, pues, admitir una correspondencia entre las dos frases trimembres tomadas en consideración. Las referencias doctrinales básicas serían las mismas en una y en otra, pero con una diferencia en el primer miembro. El «acercarse/creer» reflejaría la perspectiva del hombre, indicando lo que ha de hacer, mientras que «sacramento de piedad» reflejaría la perspectiva de Dios, mostrando su amor en el tirar del hombre para que se acerque a Cristo, esto es, para que crea en él.

11. La última terna -poco perceptible a nivel literario- coincide con la conclusión del parágrafo: «No sienta repugnancia de la trabazón de los miembros, no sea un miembro podrido que merezca ser amputado, no sea deforme que deba ruborizarse por ello; sea bello, sea proporcionado, sea sano, adhiérase al cuerpo // viva de Dios para Dios // fatíguese ahora en la tierra, para reinar después en el cielo»57. Los miembros de la terna aparecen separados con la doble barra. También aquí percibimos una correspondencia entre ellos y los de la primera terna, constatando que se modifica el orden de sucesión. De hecho, el orden 1,2,3 de la primera aparece en esta última como 2,3,1. El primer miembro de esta última es relativamente largo; por eso traemos aquí sólo sus últimas palabras, que constituyen como el núcleo: «adhiérase al cuerpo». Adherirse es entrar en unidad. En el caso concreto, unidad en Cristo con el Cuerpo de Cristo. Nos hallamos, pues, de nuevo en la misma onda del signum unitatis que es la Eucaristía. El segundo miembro de la terna está constituido por estas palabras: «vida de Dios para Dios». Con este «de Dios» san Agustín suele referirse al Espíritu Santo

56 Ib. 26 2. 3. «Non enim ad Christum ambulando currimus, sed credendo; nec motu corporis sed uoluntate corporis accedimus» (Io. eu. tr. 26,3).

57 Ib. 26,13: «non abhorreat a compage membrorum, non sit putre membrum quod resecari mereatur, non sit distortum de quo erubescatur; sit pulcrum, sit aptum, sit sanum, haereat corpori, uiuat deo de deo; nunc laboret in terra, ut postea regnet in caelo». 
en cuando donante del amor ${ }^{58}$. Por tanto, también aquí nos encontramos en la onda del uinculum caritatis que es la Eucaristía. Queda el último miembro de la terna que corresponde a las palabras: «fatíguese ahora en la tierra para reinar después en el cielo». Nuestro interés no está en lo que el predicador ordena hacer -fatigarse en la tierra-, sino en la finalidad por la que ordena hacerlo: «para reinar después en el cielo». Con otras pálabras, topamos una vez más con el concepto de vida eterna. ¿Por qué el predicador utiliza este argumento? Porque con anterioridad, como hemos visto, había mostrado ya que poseer la vida eterna es un vivo deseo del hombre. De nuevo, el miembro de esta terna que dice referencia al primero de la terna inicial manifiesta cuál es el deseo último del hombre. Y justamente por ser el deseo último, el objetivo al que todo ha de ir encaminado, cierra el parágrafo y pone fin al comentario de la primera parte del texto juánico comentado en el Tratado 26 (Jn 6, 41-51).

12. Presentamos ahora en visión sintética y esquemática las cuatro ternas, para luego sacar las conclusiones:

$\begin{array}{llll} & \text { 1er miembro } & 2^{\circ} \text { miembro } & \text { 3er miembro } \\ \text { Terna a): } & \text { Sacramento de piedad } & \text { Signo de unidad } & \text { Vínculo de caridad } \\ \text { Terna b): } & \text { Quien desee vivir } & \text { Tiene donde vivir } & \text { Tiene de qué vivir } \\ \text { Terna c): } & \text { Acérquese/crea } & \text { Incorpórese } & \text { Ser vivificado } \\ \text { Terna d): } & \text { Para reinar en el cielo } & \text { Adhiérase al Cuerpo } & \text { Viva de Dios }\end{array}$

Conclusiones que pueden extraerse:

1. La terna b) deja claro que el concepto de vida es común a los tres miembros; es la vida lo que está en juego en todos ellos. Por supuesto, se trata de la vida eterna, que es la que va ligada al comer el pan eucarístico.

2. Resulta claro que el segundo miembro gira en todas las ternas en torno a la idea de unidad: la vida va vinculada a la unidad como lugar "en dónde" -terna b)-. Las ternas c) y d) especifican de qué unidad se trata: de la unidad en un Cuerpo (incorporarse, adherirse al Cuerpo) que obviamente es el Cuerpo de Cristo, y aclaran el impreciso «donde» de la terna b). La referencia a Cristo (=Hijo) es obvia.

58 S. 34,2,3: «Certe quia dixi, Caritas Dei diffusa est in cordibus nostris per Spiritum Sanctum qui datus est nobis (Rom 5,5); ideo consequens est ut quia Spiritus sanctus Deus est, nec diligere possumus Deum, nisi per Spiritum Sanctum, amemus Deum de Deo. Hinc est ergo consequens». Cf. Ep. Io. tr. 7,4ss. 
3. Resulta igualmente claro que el concepto de vida es predominante en el tercer miembro: ternas b), c) y d). Pero aquí la vida está relacionada con la caridad, aunque como lugar "de dónde", como origen (terna b). Las ternas nos presentan dos «de dónde»: la caridad, en la terna a), y el Espíritu Santo, en la terna d). Esta terna, en efecto, especifica que se trata de la vida «de Dios», donde el «de» más que pertenencia indica origen, y con «Dios» se indica en concreto al Espíritu Santo. Aunque parezca que a la vida se le asigna un doble origen, en realidad el origen es único: el Espíritu Santo, del que es don la Caridad. La referencia al Espíritu Santo está clara.

4. Respecto del primer miembro ya no existe tanta claridad. También en él es importante la idea de la vida. Pero no la contempla ni en su lugar, ni en su origen, sino en el sujeto que la desea poseer -terna b)-. Si se quiere mantener el paralelismo con los otros miembros de la terna, cabe preguntar qué relación tiene la «piedad» de la terna a) con lo que encontramos en las ternas b), c) y d). ¿Quiénes son el sujeto y el objeto de esa «piedad»? ¿Hay que pensar en la piedad del hombre para con Dios, o en la piedad de Dios para con el hombre? La respuesta a la pregunta nos la aporta la terna c). La primera de las opciones indicadas puede advertir la piedad del hombre en el hecho de acercarse a Cristo, creyendo en él. Pero no nos parece acertado. En el texto agustiniano el acercarse a Cristo, aunque no deja de ser obra del hombre, es ante todo obra de Dios. Si el hombre se acerca a Cristo y cree en él es porque el Padre ha tirado de él. Leyendo el texto de san Juan y el comentario agustiniano quien aparece lleno de piedad, esto es, de amor, no es el hombre sino Dios. Nadie puede venir a mí si el Padre que me ha enviado no lo atrae; y yo lo resucitaré en el último día (Jn 6,44): he aquí la manifestación de la piedad de Dios: él tira del hombre hacia Cristo que, en cuanto pan de vida eterna, sacia el deseo del hombre de verdad, justicia y, sobre todo, de eternidad (terna d): Esta interpretación muestra también que se trata de la «piedad» de Dios Padre. Ni el texto comentado ni el comentario del texto dejan otra salida razonable: una vez que en el segundo miembro de las ternas la referencia a Cristo, el Hijo de Dios, es innegable, como innegable es la referencia al Espíritu Santo en el tercer miembro, la lógica pide la referencia a Dios Padre en el primero.

PÍo DE LUIS

Estudio Teológico Agustiniano Valladolid 